EESTI NSV TEADUSTE AKADEEMIA TOIMETISED, GEOLOOGIA

ИЗВЕСТИЯ АКАДЕМИИ НАУК ЭСТОНСКОП ССР. ГЕОЛОГИЯ

PROCEEDINGS OF THE ACADEMY OF SCIENCES OF THE ESTONIAN SSR. GEOLOGY

$1985,34,1$

удК $553.64: 546.16(474.2)$

В. ФРОЛОВ, М. БЕЛЯКОВ,

Р. РАУДСЕП, Х. ЛИНВРАНД

\title{
ФТОР В ФОСФАТОНОСНЫХ ПОРОДАХ МЕСТОРОЖДЕНИЯ РАКВЕРЕ
}

В осадочных фосфатоносных породах содержание фтора, тесно связанного с фосфатами, более значительно $(4-5 \%)$, чем в других минералах (до $0,1 \%)$. При этом в большинстве случаев устанавливаются близкие к функциональным корреляционные связи между фтором и фосфором $\left(\mathrm{P}_{2} \mathrm{O}_{5}\right)$. Величины отношения $\mathrm{F}: \mathrm{P}_{2} \mathrm{O}_{5}$ в осадочных фосфоритных рудах в зависимости от их возрастных и генетических особенностей варьируют от $0,08-0,09$ до $0,13-0,14$. Например, минимальные значения здесь приурочены к нижнеордовикским органогенным фосфатоносным образованиям Прибалтики, а максимальные - к верхнеюрским хемогенным желваковым фосфатам центральной части Русской платформы. Выяснение закономерностей распределения фтора среди фосфатоносных пород и особенностей его взаимосвязей с фосфором способствует более полному изучению этого полезного ископаемого и может иметь важное прикладное значение.

В монографии Б. М. Гиммельфарба (1965; всего лишь по 4 анализам) и в работе А. И. Смирнова (1972; по 12 анализам) опубликованы данные о содержании фтора и значениях отношения $\mathrm{F}: \mathrm{P}_{2} \mathrm{O}_{5}$ в Прибалтийском фосфоритоносном бассейне. Немногочисленные данные о фтороносности эстонских фосфоритов приведены во многих работах (Koch, 1958; Лоога, 1962; Петерселль и др., 1981). Опубликованные данные о фтороносности пород недавно открытого месторождения Раквере отсутствуют (Раудсеп, Эскель, 1980). При поисках и разведке месторождений фосфоритов выполнены химические определения фтора (для Тоолсе 120 , для Азери 55 и для Раквере 245 проб), однако из-за недостаточной точности они в настоящей статье не учитываются.

Основная причина неполноты данных по фтору в фосфатоносных породах - это трудность точного определения его малых количеств (до $2-3 \%$ ) классическими химическими методами анализа. В настоящее время открылась возможность значительно повысить точность и одновременно экспрессность анализа малых содержаний фтора в породах нейтронно-активационным методом, точность и порог чувствительности которого $0,03-0,04 \%$. Этот метод основывается на измерении интенсивности гамма-излучения азота-16, образующегося из фтора-19 под воздействием потока быстрых нейтронов. Новообразованный изотоп азота-16 характеризуется высокой энергией гамма-квантов, которые четко регистрируются с помощью сцинтилляционного гаммаспектрометра. Содержание фтора в породе устанавливается с помощью соответствующих градуировочных графиков или расчетным путем.

Целью настоящей статьи является охарактеризовать фтороносность фосфоритов * и фосфатсодержащих пород разведываемого месторож-

* Принятая в работе классификация соответствует «Геологическому словарю (1978, т. 2), по которому фосфориты - это породы, содержащие более $18 \% \mathrm{P}_{2} \mathrm{O}_{5}$. 


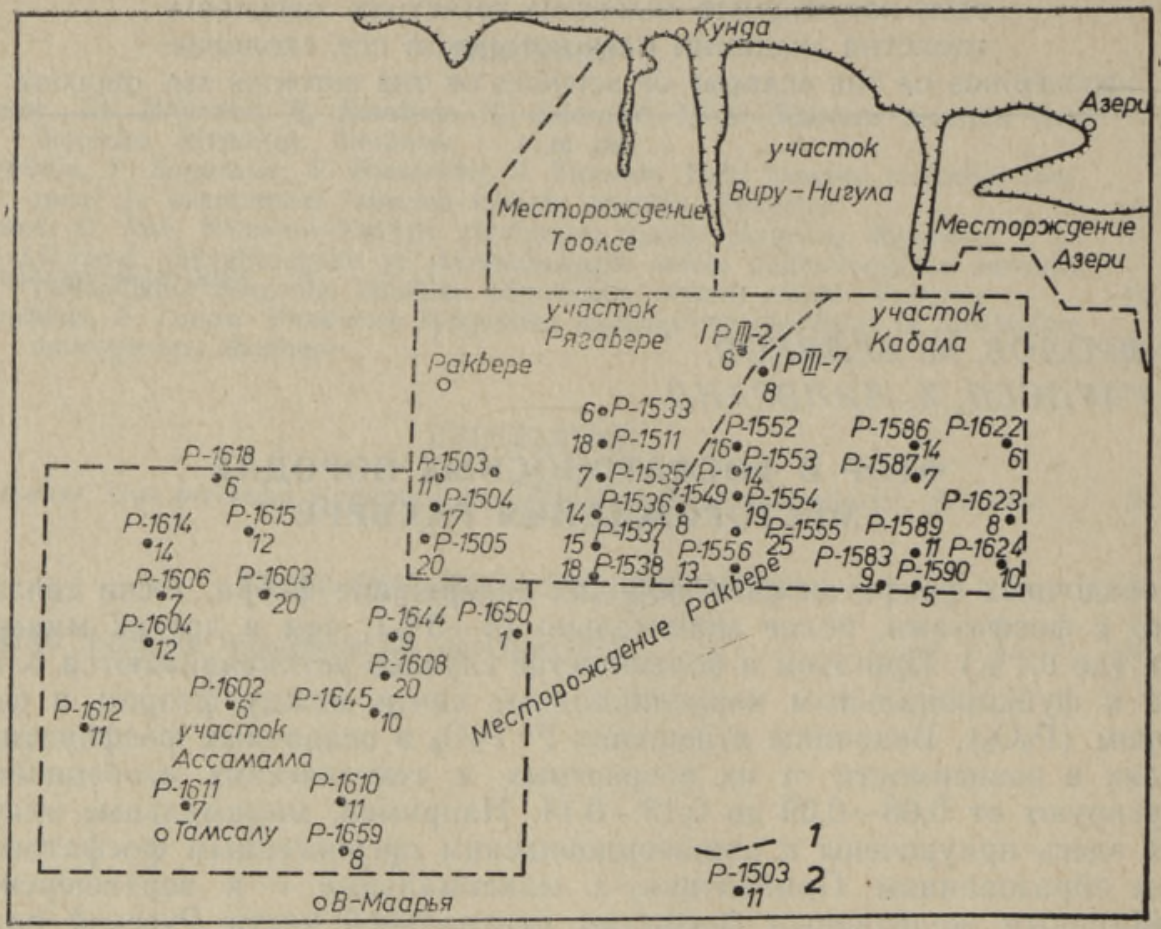

Рис. 1. Схема опробования. 1 - границы месторождений и участков; 2 - точка опробования и количество отобранных проб.

дения Раквере (рис. 1). Геологическое изучение и опробование фосфоритоносных отложений осуществляли Р. Раудсеп и Х. Лийвранд (УПравление геологии ӘССР), аналитические работы и геохимические исследования - В. Фролов и М. Беляков (ГИГХС).

На месторождении из керна 40 буровых скважин, относительно равномерно расположенных на рассматриваемой площади, были отобраны и изучены 470 проб, из которых фосфориты составили 80 , фосфатсодержащие породы 350 и вмещающие породы 40 проб. Фосфатоносная толща месторождения сложена породами каллавереской свиты нижнего ордовика: кварцевыми песчаниками, детритистыми и детритовыми кварцевыми песчаниками, детрититами, ракушняками и др. (Раудсеп, Хазанович, 1980). Мощность толщи колеблется в пределах от 1,5 до 12,9 м.

В целях оценки распределения фтора в фосфатах кальция и в разных группах пород в работе были использованы значения отношения $\mathrm{F}: \mathrm{P}_{2} \mathrm{O}_{5}$. Последние в наибольшей степени информативны для пород, содержащих более $30 \%$ фосфатов кальция (более $12 \%, \mathrm{P}_{2} \mathrm{O}_{5}$ ). В породах же с относительно низкими содержаниями $\mathrm{P}_{2} \mathrm{O}_{5}$ (менее 8-10\%) на значения отношения $\mathrm{F}: \mathrm{P}_{2} \mathrm{O}_{5}$ возможно некоторое влияние фтора, содержащегося в нефосфатных минералах - в амфиболах, сфене, турмалине и в ряде других акцессорий. Не исключается и присутствие малых количеств флюорита. Қак показали исследования, количество фтора, не связанного с фосфатами, обычно не превышает в породах $0,04-0,05 \%$ и оно способно оказать некоторое существенное влияние на показатели отношения $\mathrm{F}: \mathrm{P}_{2} \mathrm{O}_{5}$ только в породах с низкими содержаниями $\mathrm{P}_{2} \mathrm{O}_{5}$, что учтено в интерпретации результатов.

В латеральном направлении низкокачественные руды, представленные преимущественно кварцем, сменяются высококачественными, кото- 


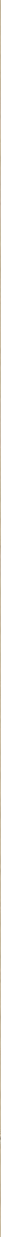

Рис. 2. Диаграммы распределения фтора и отношения $\mathrm{P}_{2} \mathrm{O}_{5}$ по геохимическим пачкам.

рые состоят в основном из фосфатного детрита и створок раковин беззамковых брахиопод. Все это на данной стадии изученности не позволяет обеспечить строгую привязку результатов опробования исследований к их стратиграфическим разделениям фосфатоносного разреза. Поэтому для удобства последующего изложения материалов предлагается условно разделить разрез на 3 геохимические пачки - А, Б и В. В нижнюю пачку А включены отложения маардуской (около 3 м) и низов суурйыгиской пачки (до 3 м). В пачке Б рассматриваются отложения, развитые в средней части разреза суурйыгиской пачки (до $2-3$ м), а в пачке В - ее верхние слои (до 3 м).

Фосфатоносные образования в выделяемых геохимических пачках отличаются разной степенью концентрации фтора в фосфатах кальция - максимальные значения в породах пачек А и В, а минимальные - в пачке Б (рис. 2). Содержание фтора, соответствующее $39,5 \%$ $\mathrm{P}_{2} \mathrm{O}_{5}$, в мономинеральном фосфате пачек $\mathrm{A}$ и В в среднем составляет $3,3 \%$ (37 проб), а в пачке Б-3,6\% (43 пробы).

В соответствии с отмеченными концентрациями фтора в продуктивном разрезе мономинеральных фосфатов распределены значения отношения $\mathrm{F}: \mathrm{P}_{2} \mathrm{O}_{5}$ для пород и руд. Проиллюстрировать сказанное представляется удобным на примере отложений, вскрытых буровой 


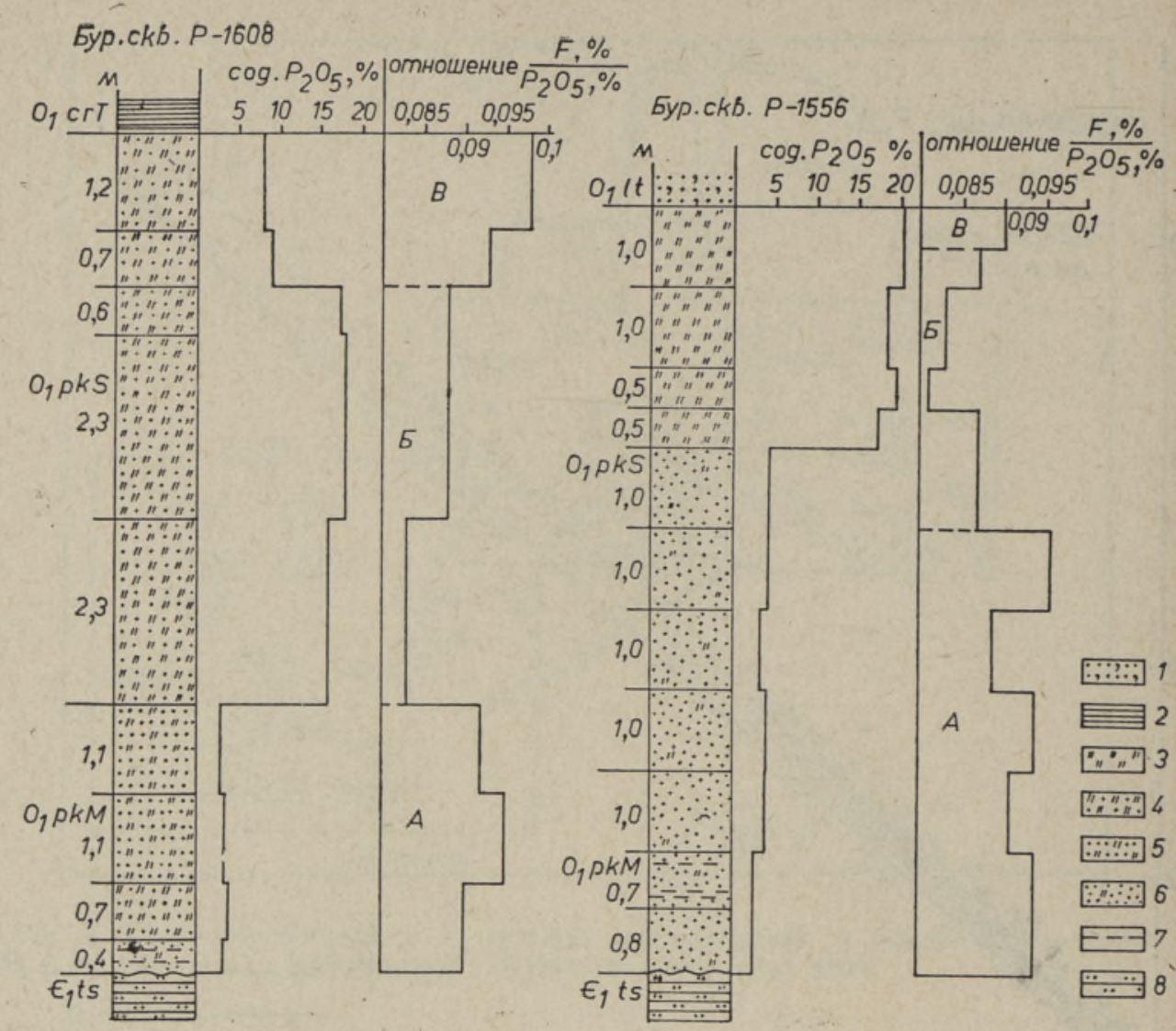

Рис. 3. Диаграммы распределения фосфата и отношения $\mathrm{F}: \mathrm{P}_{2} \mathrm{O}_{5}$ по разрезам фосфатоносной толщи. 1 - глауконитовый песчаник; 2 - граптолитовый аргиллит; 3 детритит; 4 - детритовый песчаник; 5 - детритистый кварцевый песчаник; 6 кварцевый песчаник; 7 - прослойки глины; 8 - алевролит.

скважиной P-1608 (рис. 3). Она пройдена на западе месторождения (сев. уч. Ассамалла), где продуктивная толща перекрыта аргиллитамн цератопигевого горизонта, и, в принципе, существует наибольшая возможность обнаружить все подразделения рассматриваемого разреза (изменчивость мощностей в данном случае не учитывается). Выделяемые в фосфатоносном разрезе геохимические пачки достаточно четко обозначены показателями отношения $\mathrm{F}: \mathrm{P}_{2} \mathrm{O}_{5}$ (рис. 3). Соответственно эти значения составляют: в пачке А $0,090-0,095$; в пачке Б $0,083--$ 0,088 ; в пачке В $0,093-0,098$. Эти же геохимические пачки по показателям $\mathrm{F}: \mathrm{P}_{2} \mathrm{O}_{5}$ прослежены и в той части месторождения, где из разреза выпадают слои цератопигевого возраста и, видимо, верхние слои фосфатоносной толщи (скв. Р-1556, уч. Кабала). Выделяемые на рис. 3 геохимические пачки А и Б характеризуются бо́льшими мощностями, чем в вышерассмотренном разрезе, что не согласуется с очень малой мощностью пачки В. Данное обстоятельство, видимо, отражает раз- мыв верхних горизонтов фосфатоносной толщи. Значения показателей отношения $\mathrm{F}: \mathrm{P}_{2} \mathrm{O}_{5}$ в рассматриваемых пачках $\mathrm{A}$, Б и В соответственно составляют $0,089-0,096 ; 0,081-0,087$ и 0,09 .

Из рассмотренного выше достаточно наглядно явствует, что абсолютного тождества фтор-фосфорных показателей при выделении пачек А, Б и В ожидать не следует. Отчасти это связано с размывом и фациальными особенностями фосфатоносных образований, но не в мень- 
Показатели отношения $\mathrm{F}: \mathrm{P}_{2} \mathrm{O}_{5}$ в фосфоритах месторождения Раквере

\begin{tabular}{|c|c|c|c|c|c|c|}
\hline \multirow{2}{*}{$\begin{array}{l}\text { Геохими- } \\
\text { ческие } \\
\text { пачки }\end{array}$} & \multirow{2}{*}{$\begin{array}{l}\text { Число } \\
\text { проб }\end{array}$} & \multicolumn{3}{|c|}{$\mathrm{P}_{2} \mathrm{O}_{5}, \%$} & \multicolumn{2}{|c|}{$\mathrm{F}: \mathrm{P}_{2} \mathrm{O}_{5}$} \\
\hline & & & & средний & крайние & средний \\
\hline $\begin{array}{l}\mathrm{B} \\
\mathrm{B} \\
\mathrm{A}\end{array}$ & $\begin{array}{l}20 \\
43 \\
17\end{array}$ & $\begin{array}{l}16,8 \\
16,8 \\
17,2\end{array}$ & $\begin{array}{l}27,4 \\
24,9 \\
24,1\end{array}$ & $\begin{array}{l}21,0 \\
20,6 \\
19,9\end{array}$ & $\begin{array}{l}0,088-0,096 \\
0,081-0,086 \\
0,088-0,096\end{array}$ & $\begin{array}{l}0,091 \\
0,084 \\
0,091\end{array}$ \\
\hline
\end{tabular}

шей степени факт относительного разнообразия значений отношения $\mathrm{F}: \mathrm{P}_{2} \mathrm{O}_{5}$ можно объяснить их искажением в породах с низкими содержаниями фосфатов кальция. Описанный характер закономерностей распределения фтора в фосфатоносном разрезе подкрепляется статистически обработанными данными выборок проб фосфоритов, сгруппированных по пачкам и наиболее представительных и информативных в рассматриваемом вопросе (таблица).

Из таблицы видно, что по степени концентрации фтора $\left(\mathrm{F}: \mathrm{P}_{2} \mathrm{O}_{5}\right)$ в фосфатах кальция геохимические пачки А, Б и В выделяются достаточно контрастно. Представляется, что обнаруженные особенности фтор-фосфорных взаимосвязей найдут применение в корреляции фосфатоносных разрезов при поисково-разведочных работах, что будет способствовать их успешному завершению.

Не менее интересной представляется открывающаяся здесь перспектива использования фтора для экспресс-анализа $\mathrm{P}_{2} \mathrm{O}_{5}$ в стволе буровой скважины при каротажных работах и для уточнения мощностей продуктивного слоя. Исходя из имеющихся результатов при опробовании корреляционным методом фосфатоносных образований по выделяемым геохимическим пачкам $\mathrm{A}, \mathrm{B}$ и $\mathrm{B}$, ошибки содержаний $\mathrm{P}_{2} \mathrm{O}_{5}$ не превысят $\pm 3-4$, а в среднем составят $\pm 1,5-2,0$ отн. $\%$. Такие предпосылки позволяют надеяться на то, что методы экспрессного опробования полезного компонента внесут свой вклад в дело изучения фосфатного сырья Прибалтики и смогут способствовать повышению эффективности поисково-разведочных работ. В практике поисково-разведочных работ на месторождениях Малого Каратау (Кошелев и др., 1975) при помощи каротажных работ в скважинах осуществляется экспрессный анализ $\mathrm{P}_{2} \mathrm{O}_{5}$ по корреляции со фтором.

\section{Л И Т Е Р А Т У Р А}

Гиммельфарб Б. М. Закономерности размещения месторождений фосфоритов СССР и их генетическая классификация. М., 1965.

Кошелев Н. П., Беленко Р. Д., Шварцман Н. П. Результаты применения комплекса ядерно-физических методов исследования скважин фосфоритовых месторождений бассейна Малого Каратау. - В кн.: Ядерно-физические методы опробования скважин на месторождениях фосфоритов, апатитов и плавикового шпата. Алма-Ата, 1975.

Лоог А. Р. О фосфатном материале оболовых фосфоритов. - Изв. АН ЭССР, серия физ. мат. и техн. наук, 1962, XI, 229-235.

Петерселль В., Минеев Д., Лоое А. О минералогии и геохимии оболовых песчаников и диктионемовых сланцев Северной Эстонии. - Уч. зап. Тартуского гос. ун-та, $1981,561,30-49$.

Paydcen P., Хазанович K. Классификация литологических разновидностей ракушечных фосфоритов Прибалтийского фосфоритоносного бассейна. - Изв. АН ЭССР. Геол., 1980, 29, 147-153.

Paydcen P., Эскель Ю. Особенности геологического строения фосфоритоносной толщи южнее месторождения Тоолсе. - Изв. АН ЭССР. Геол., 1980, 29, 84-86. 
Смирнов А. Н. Вещественный состав и условия формировання основных типов фосфоритов. М., 1972.

Koch, R. Oobolusfosforiidi koostisest ja omadustest. - ENSV TA Toim. Tehn. ja füüs.mat. seeria. 1958, VII, 328-329.

\section{Государственный научно-исследовательский институт горно-химического сырья}

Поступила в редакцию 2/IX 1983

Управление геологии Эстонской ССР

V. FROLOV, M. BELJAKOV,

R. RAUDSEP, H. LIIVRAND

\section{FLUOR RAKVERE MAARDLA FOSFAATSETES KIVIMITES}

Fluori sisalduse määramine kivimites keemilise analüüsi teel pole seni taganud määrangute täpsust. Artiklis esitatud fluori määrangud Rakvere maardla pōhjaosa fosfaatsetest kivimitest (oobolusliivakividest) on tehtud neutronaktiivsel meetodil, mille eeliseks on tulemuste suur täpsus (meetodi tundlikkuspiir on $0,03-0,04 \%$, suhteline viga ei ületa $\pm 1,5-2 \%$ ) ja tööde teostuskiirus.

Et põhiosa kivimites sisalduvast fluorist on seotud käsijalgsete kodade poolmetes ja detriidis oleva fosfaadiga, siis osutub kõige informatiivsemaks karakteristikuks fluori ja $\mathrm{P}_{2} \mathrm{O}_{5}$ suhe $\left(\frac{\mathrm{F}}{\mathrm{P}_{2} \mathrm{O}_{5}}\right)$. Viimane on oobolusliivakivide läbilōigete eri osades erinev: keskmiselt 0,091 läbilōike alumises ja ülemises ning 0,084 keskmises osas. Suhte muutumise järgi võib fosfaatsed kivimid jagada kolme geokeemilisse kihistikku.

Andmeid fluori sisalduse kohta on võimalik kasutada oobolusliivakivide erinevate läbilőigete korrelatsiooni kindlakstegemiseks ja ka $\mathrm{P}_{2} \mathrm{O}_{5}$ sisalduse määramiseks kivimeis kiirmeetodil.

\section{FROLOV, M. BELYAKOV,}

R. RAUDSEP, H. LIIVRAND

\section{FLUOR IN THE PHOSPHATE ROCKS OF THE RAKVERE DEPOSIT}

The determination by chemical analysis of the content of fluor in rocks has not as yet proved to be of sufficient accuracy. The determination of the fluor content in the phosphate rocks of the northern part of the Rakvere deposit (in obolus sandstones), as proposed by the author, has been carried out by the neutron-active method, the advantages of which are the considerable accuracy of the results (the sensitivity limit being $0.03-0.04 \%$, the relative error not exceeding $\pm 1.5-2 \%$ ) and the speed of the calculating operations.

Since the main part of the fluor content in the rocks is connected with the phosphate contained in the valves and in the detritus of the brachiopod shells, the

most informative character seems to be the relation of the fluor to $\mathrm{P}_{2} \mathrm{O}_{5} \quad\left(\frac{\mathrm{F}}{\mathrm{P}_{2} \mathrm{O}_{5}}\right)$. The value of the latter fluctuates in different parts of the section, being on the average 0.091 in the lowermost and uppermost parts, and 0.084 in the middle. According to the change in that ratio, the phosphate rocks can be divided into three geochemical members.

The data on the fluor content may be used for determining the correlation of different sections of obolus limestones and also for the assessment of the $\mathrm{P}_{2} \mathrm{O}_{5}$ content by a speedy method. 